\title{
Paralytic ileus and dementia in a case of myxoedema
}

\author{
R. J. BENTLEY \\ M.B., B.Chir., F.R.C.S. \\ R. J. S. BROWNE \\ M.B., B.S. \\ Senior Surgical Registrar House Physician, Geriatric Unit \\ University College Hospital, \\ London, W.C.1
}

DemENTIA and abdominal symptoms due to diminished intestinal motility are both complications of myxoedema. The onset of myxoedema may be so insidious that the true cause of the dementia may be overlooked. The following is a description of such a patient who developed acute paralytic ileus which was apparently due to non-occlusive intestinal ischaemia.

\section{Case report}

Mrs L.F. (aged 79 years) was admitted to $\mathrm{St}$ Pancras Hospital on 7 August 1968 from a Welfare Home, where she had been resident for 4 years, because of progressive dementia. For a week she had become increasingly lethargic and confused and two generalized convulsions had been observed. She complained of lower abdominal pain for 4 days and had been vomiting for $24 \mathrm{hr}$.

On examination she was clinically myxoedematous, confused, difficult to rouse and dehydrated, pulse 72 , blood pressure $90 / 30$ and temperature $95^{\circ} \mathrm{F}$. The abdomen was tense and distended with generalized tenderness and rebound tenderness. Very occasional bowel sounds were heard and the rectum was empty. Straight X-rays of the abdomen suggested a lower intestinal obstruction. Treatment was started with gastric suction and intravenous infusion but her condition continued to deteriorate, and in view of the clinical signs of early peritonitis laparotomy was performed.

A right paramedian incision was made. There was much free serous fluid and the whole of the small intestine, apart from a short segment of proximal jejunum and terminal ileum, was grossly dilated and without peristalsis. There was no obstructing lesion distal to the dilated segment, which was purple, with congestion of the serosal arteries and veins. There was no visible pulsation in any of the mesenteric arteries but neither the arteries nor veins were thrombosed. The abdominal aorta was arteriosclerotic but pulsating weakly. The colon was normal. While the small bowel was delivered the dilated segment rapidly became much colder than the normal segments at either end.
It was deduced that the abnormal segment was relatively ischaemic causing paralytic ileus. The bowel appeared to be viable and after decompression through a proximal enterotomy it was returned to the abdomen which was then closed.

Five hundred millilitres of Rheomacrodex were given in theatre with blood to maintain the central venous pressure. The diagnosis of myxoedema yas confirmed by the PBI of less than $1 \mu \mathrm{g} / 100 \mathrm{ml}$. Other investigations showed: haemoglobin, $90 \%$; blood urea, $157 \mathrm{mg} / 100 \mathrm{ml}$; sodium, $131.0 \mathrm{mEq} / \mathrm{l}$; potassium, $3.2 \mathrm{mEq} / 1$; bicarbonate, $28.0 \mathrm{mEq} / 1$; chloride, $88.0 \mathrm{mEq} / 1$; serum cholesterol, $255.0 \mathrm{mg} /$ $100 \mathrm{ml}$; Shumm's test for methaemalbumen weakly positive.

Treatment of her myxoedema was commenced with tri-iodothyronine given as a continuous dilute intravenous infusion starting with $60 \mu \mathrm{g} \mathrm{12-hourly.}$ In addition further infusions of Rheomacrodex and large doses of hydrocortisone and ampicillin were given (Fig. 1). Within a few hours she developed an intermittent tachycardia up to 200 /min with supraventricular ectopics. The dose of tri-iodothyronine was reduced to $10 \mu \mathrm{g}$ 12-hourly but was stopped after $24 \mathrm{hr}$ when the arrhythmia persisted. She was digitalized with good effect.

By the 3rd day bowel sounds were present and gastric aspirates reduced, she was alert and responsive with a normal temperature and the blood urea was falling. On the 5th day intravenous triiodothyronine $5 \mu \mathrm{g}$ 12-hourly was restarted. A week post-operatively, however, the abdomen became more distended and tender, bowel sounds were reduced and absolute constipation returned. The wound appeared infected. It was felt that ischaemia might have recurred, and a further $500 \mathrm{ml}$ of Rheomacrodex was given without improvement. Laparotomy was again undertaken. There was an extensive wound abscess with disruption of the muscle layers. Much clear ascitic fluid was drained but the small bowel appeared normal and peristalsis was observed. Post-operative adhesions prevented examination of the mesenteric vessels and the abdomen was again closed.

Recovery was further complicated by broncho- 

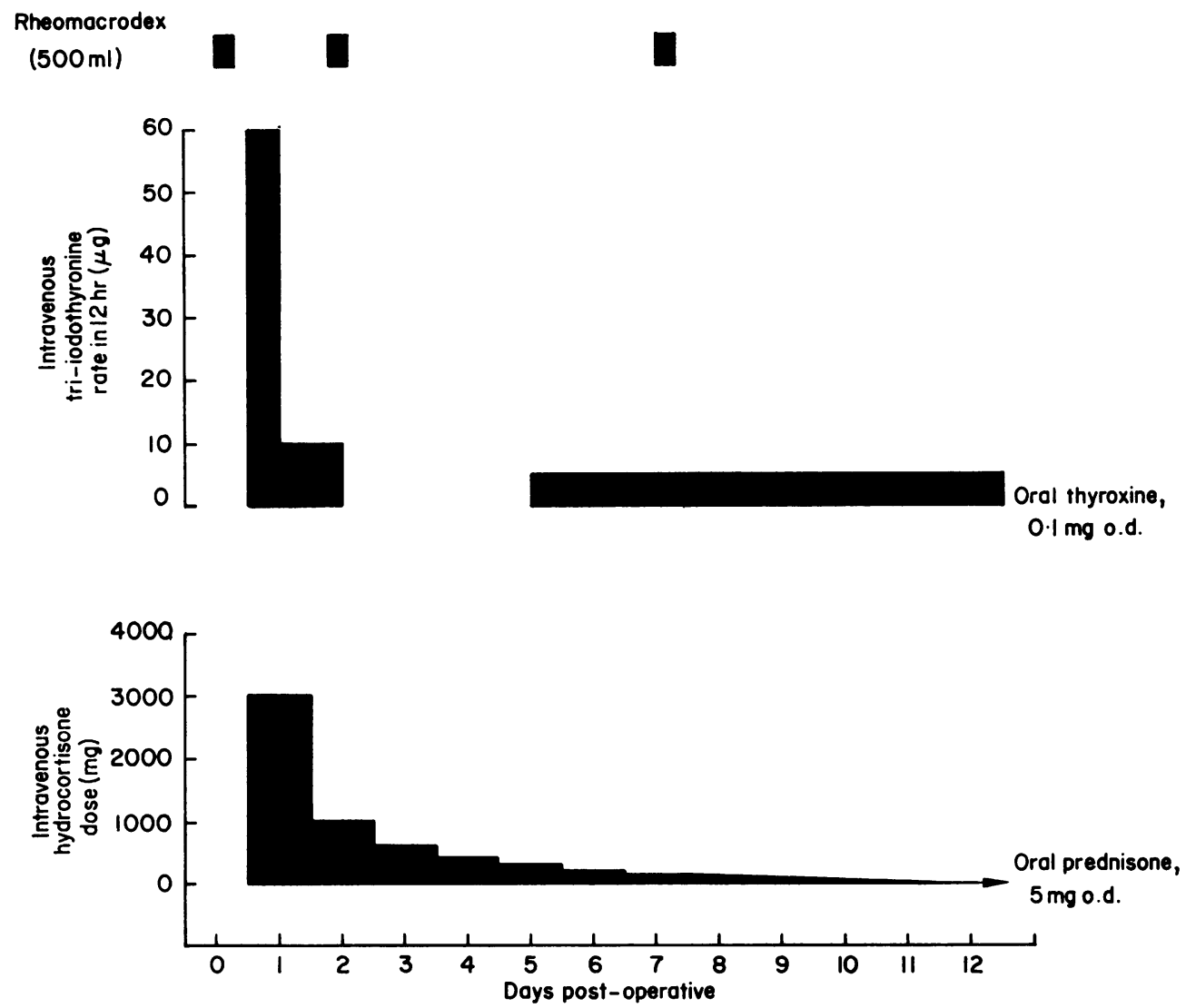

FIG. 1. Mrs L.F. post-operative therapy.

pneumonia and a small pulmonary embolus, but eventually normal feeding and bowel actions were established. After 2 weeks L-thyroxine $0.1 \mathrm{mg}$ daily was substituted for tri-iodothyronine and the dose was subsequently increased to $0.2 \mathrm{mg}$ daily.

\section{Discussion}

Diminished intestinal motility in myxoedema is ascribed to myxoedematous infiltration of the bowel wall. This affects particularly the colon which becomes thickened, elongated and distended progressing occasionally to intestinal obstruction due to paralytic ileus (Bastenie, 1946).

In our patient the colon was macroscopically normal and paralytic ileus appeared to be caused by ischaemia of the small bowel without occlusion of major vessels (non-occlusive intestinal ischaemia).

Descriptions of this entity show that it is particularly associated with low output cardiac failure, digoxin intoxication and increased blood viscosity. The bowel shows haemorrhagic necrosis of the mucosa and there is a high mortality, death occuring
3-5 days after the onset of abdominal pain (Fogarty $\&$ Fletcher, 1966). A positive Shumm's test has been described in massive infarction of the small bowel (Bank et al., 1968).

Low cardiac output and increased circulation time are features of myxoedema. It has also been shown that a fall in body temperature causes increased blood viscosity and arteriolar constriction (Suzuki \& Penn, 1965). Presumably a combination of these factors together with hypotension and gross arteriosclerosis led to peripheral mesenteric vascular shut-down in this patient (Marston et al., 1966).

The dangers of intestinal ischaemia are not only gangrene and peritonitis but also irreversible shock due either to absorption of endotoxins or hypovolaemia caused by fluid loss into the bowel (Marston, 1964). Investigation and comparison of different forms of therapy in dogs in which shock has been induced by the injection of endotoxin has shown the effectiveness of massive hydrocortisone therapy combined with low molecular weight Dextran 
(Lillehei et al., 1967). This is attributed to the vasodilator and positive inotropic action of such large doses of hydrocortisone. Similar therapy was successful in our patient.

Recent reports recommend that a rapidly acting thyroid hormone should be promptly administered to patients in myxoedema coma or pre-coma. The danger, particularly to the cardio-vascular system, must be balanced against the patient's need for urgent replacement of thyroid hormone.

There are conflicting recommendations for the choice of drug (L-thyroxine or tri-iodothyronine), the method of administration (intravenously or orally) and the dose (Rosenberg, 1968). Dyson \& Wood (1956) suggest that $100 \mu \mathrm{g}$ of tri-iodothyronine intravenously every $12 \mathrm{hr}$ is adequate in coma and should not be exceeded. Ivy (1965) recommends that in pre-coma the initial dose should be $25 \mu \mathrm{g}$ of tri-iodothyronine 12-hourly, which should be increased if the level of consciousness falls. Serious cardiac arrhythmia has been precipitated with as little as $10 \mu \mathrm{g}$ intravenously given as a single dose albeit combined with metaraminol (Perlmutter \& Cohn, 1964) and this writer recommends oral administration. Tri-iodothyronine is said to have a measurable effect after $6 \mathrm{hr}$ and reach its maximum effect after 48-72 hr (Asper, Selenkow \& Plamondon, 1953). There would seem, therefore, to be no advantage in giving the drug as a continuous infusion.

The patient has now returned to her Welfare Home. When seen 3 months after this illness she was alert, mobile and able to hold a rational conversation. Her appetitite was normal and the clinical signs of myxoedema had receded.

\section{Acknowledgments}

We would like to thank Dr A. N. Exton-Smith and $\mathrm{Mr}$ G. L. Bunton for permission to publish this case.

\section{References}

Asper, S.P., Selenkow, H.A. \& Plamondon, C.A. (1953) A comparison of the metabolic activities of tri-iodothyronine and thyroxine in myxoedema. Bull. Johns Hopk. Hosp. 93, 164.

Bank, S., Barbezat, G.O., Marks, I.N. \& Silber, W. (1968) Methaemalbuminaemia in acute abdominal emergencies. Brit. med. J. 2, 86.

BASTENie, P.A. (1946) Paralytic ileus in severe hypothyroidism. Lancet, $\mathbf{i}, 413$.

Dyson, A. \& WooD, M.W.W. (1956) Tri-iodothyronine in myxoedema coma. Lancet, ii, 757.

FogaRTY, T.J. \& FleTCHER, W.S. (1966) Genesis of nonocclusive mesenteric ischaemia. Amer. J. Surg. 111, 131.

Ivy, H.K. (1965) Myxoedema pre-coma. Mayo Clin. Proc. 40, 403.

Lillehei, R., Deitzman, R., Movsas, S. \& Bloch, J.H. (1967) Treatment of septic shock. Mod. Treatm. 4, 321.

Marston, A. (1964) Patterns of intestinal ischaemia. Ann. roy. Coll. Surg. 35, 151.

Marston, A., Pheils, M.T., Lea Thomas, M. \& Morson. B.C. (1966) Ischaemic colitis. Gut, 7, 1.

Perlmutter, M. \& Cohn, H. (1964) Myxoedema crisis of pituitary or thyroid origin. Amer. J. Med. 36, 883.

Rosenberg, I. (1968) Hypothyroidism and coma. Surg. Clin. N. Amer. 48, 353.

Suzuki, M. \& PenN, I. (1965) A reappraisal of the microcirculation during general hypothermia. Surgery, 56, 1049.

\section{Acute arteriomesenteric duodenal ileus as a complication following operative correction of scoliosis}

\author{
R. C. L. Feneley \\ M.B., M.Chir., F.R.C.S.
}

\author{
D. MaCDOnALD \\ M.B., Ch.B., F.R.C.S.(Ed.)
}

Bristol Royal Infirmary

A MILD degree of paralytic ileus may follow operative procedures on the spine, but these episodes are usually transient. The insidious onset of a mechanical intestinal obstruction under these circumstances may present a diagnostic problem which can lead to serious consequences if unrecognized (Schaffer, 1962).

This report concerns the development of acute arteriomesenteric duodenal ileus as a post-operative complication following treatment of a severe scoliosis by the Harrington Rod Technique (Harrington, 1962). Previous reports of this condition have appeared under various titles including The Cast
Syndrome (Dorph, 1950) and the Superior Mesenteric Artery Syndrome (Kaiser, McKain \& Schumacker, 1960).

\section{Case report}

T.M. aged 12 years. This girl with Marfan's Syndrome had a rapidly progressive idiopathic scoliosis. In her past history she had a ventricular septal defect closed successfully at 6 years of age, but there were no previous gastro-intestinal symptoms.

In 1963, when she was aged 8 years, the dorsal scoliosis was a prominent curvature convex to the right with an angulation subtended at the apex at 